\title{
Is hypoalbuminemia a prognostic risk factor for contrast-induced nephropathy in peritoneal dialysis patients?
}

This article was published in the following Dove Press journal:

Therapeutics and Clinical Risk Management

3 October 2014

Number of times this article has been viewed

\section{Kamal Hassan ${ }^{1,2}$ \\ Hassan Fadi $^{3}$}

'Faculty of Medicine in the Galilee, Bar-Ilan University, Safed, Israel; ${ }^{2}$ Peritoneal Dialysis Unit, Galilee Medical Center, Nahariya, Israel; ${ }^{3}$ Sackler Faculty of Medicine, Tel Aviv University, Tel Aviv, Israel
Correspondence: Kamal Hassan Galilee Medical Center, POB 2I, Nahariya 22100, Israel

Tel +972507887913

Fax +97249107482

Email kamal.hassan@naharia.health.gov.il
Objective: Residual renal function (RRF) is an important predictor of outcome in peritoneal dialysis (PD) patients. Hypoalbuminemia was found to be an independent risk factor for the development of acute kidney injury. We investigated the possibility of an association between serum albumin levels and the development of iodine contrast media-induced nephropathy (CIN) in PD patients.

Methods: A total of 103 PD patients who underwent invasive angiographies with exposure to iodine contrast media (ICM) were reviewed retrospectively. All patients received $0.9 \%$ saline intravenously at a rate of $75 \mathrm{~mL}$ per hour for 12 hours prior, during, and 12 hours after exposure to ICM. Acetylcysteine was given orally at a dose of $600 \mathrm{mg}$ twice daily, on the day before and on the day of exposure to ICM. The nonionic, low-osmolar contrast agent iopromide was used at a mean dose of $75.0 \pm 15.2 \mathrm{~mL}$. The changes in RRF from baseline to 1 week and 4 weeks after exposure to ICM were recorded. Outcomes of patients with serum albumin levels $<3.8 \mathrm{~g} / \mathrm{dL}$ and those with serum albumin levels $\geq 3.8 \mathrm{~g} / \mathrm{dL}$ were compared. A reduction $>30 \%$ in RRF at 7 days after exposure to ICM was considered CIN.

Results: CIN developed in 27.2\% (28/103) of patients. Of the 103 patients, $59.2 \%$ (61) had serum albumin levels $<3.8 \mathrm{~g} / \mathrm{dL}$. Of those, 37.7\% (23/61) developed CIN, compared with $11.9 \%(5 / 42)$ of those with serum albumin levels $\geq 3.8 \mathrm{~g} / \mathrm{dL}(P=0.004)$. After adjustment for all tested variables in a logistic regression with a stepwise selection model, serum albumin level at exposure to ICM was found to be the most powerful predictor of the development of CIN (odds ratio $=4.5$; confidence interval $=1.5-13.0 ; P=0.006$ ).

Conclusion: PD patients with serum albumin levels $<3.8 \mathrm{~g} / \mathrm{dL}$ should be monitored carefully when exposed to ICM. Serum albumin level may be considered a potential therapeutic target in the prevention of CIN and preservation of RRF in PD patients.

Keywords: peritoneal dialysis, renal function, iodine radio-contrast media, iodine contrast media-induced nephropathy

\section{Introduction}

Residual renal function (RRF) is conserved and persists longer in peritoneal dialysis (PD) than in hemodialysis (HD) patients. ${ }^{1}$ The preservation of RRF contributes to decreased morbidity and mortality in PD patients and may be particularly important for the effectiveness of long-term PD. . $^{2,3}$

Diabetes, congestive heart failure, peritonitis, and proteinuria are among the factors associated with an accelerated decline in RRF in PD patients. ${ }^{4,5}$ Associations between RRF and patient sex, age, and PD modality, are inconclusive. ${ }^{6}$ Loop diuretics have been shown not to affect the evolution of RRF. ${ }^{7}$ Angiotensin-converting enzyme inhibitors (ACEIs), angiotensin II receptor blockers (ARBs), and calcium-channel 
blockers (CCB) have been associated with a decreased risk of RRF decline. ${ }^{8,9}$

For the general population receiving iodine contrast media (ICM), acute kidney injury has been reported in $3 \%-14 \% .^{10-12}$ The main risk factors that have been identified for contrast media-induced nephropathy (CIN) in this population are older age, the presence of diabetic nephropathy, volume depletion, cardiac failure, liver failure, and preexisting chronic kidney disease (CKD). ${ }^{10}$ In such cases of iodine $\mathrm{CIN}$, an increase in serum creatinine concentration begins on day 2 , reaches a maximum between days 4 and 7 , and then decreases between days 7 and $21 .{ }^{10} \mathrm{CIN}$ is a multifactorial disorder with a pathogenesis that remains unclear. Reduction in renal perfusion caused by a direct effect of contrast-agent administration on the kidneys and its toxic effect on the tubular cells are usually considered the major pathophysiological factors that contribute to the development of CIN. ${ }^{13-16}$

The data are sparse regarding the potentially adverse effects of ICM administration on RRF in PD patients. ${ }^{6,10}$ Although the authors of one study were unable to identify any changes in RRF following ICM administration in PD patients, other investigators concluded that the use of ICM in this population should be counterbalanced against a critical evaluation of the risk-benefit ratio. ${ }^{3,4}$ Assessment of risk for CIN in PD patients is usually based on the findings of a few studies and on extrapolation of results from CKD patients. ${ }^{6}$ Hypoalbuminemia has been found to be an independent risk factor for the development of acute kidney injury in elderly patients, those with rhabdomyolysis, after surgery for gastric cancer, and after coronary artery bypass surgery. ${ }^{17-20}$ We are unaware of any studies that have investigated the impact of serum albumin levels on the development of CIN in PD patients. Since changes in serum creatinine levels are less sensitive in detecting small changes in RRF in dialysis patients when exposed to ICM, we set out to determine the changes in RRF from baseline to 1 week and 4 weeks after exposure to ICM in 103 stable PD patients, by using 24-hour urine collection, and to compare the outcomes between patients with serum albumin levels $<3.8 \mathrm{~g} / \mathrm{dL}$ and those with levels $\geq 3.8 \mathrm{~g} / \mathrm{dL}$.

\section{Patients and methods}

A total of 114 PD patients who underwent invasive angiographies with exposure to ICM between January 2000 and December 2013 were reviewed retrospectively. All patients received $0.9 \%$ saline intravenously at a rate of $75 \mathrm{~mL}$ per hour for 12 hours prior, during, and 12 hours after exposure to ICM in order to ensure adequate clinical hydration. Acetylcysteine was given orally at a dose of $600 \mathrm{mg}$ twice on the day before and twice on the day of exposure to ICM. PD was continued during exposure to ICM. The nonionic, low-osmolar contrast agent iopromide (Schering, Berlin, Germany) was used with a mean dose of $75.0 \pm 15.2 \mathrm{~mL}$. RRF was assessed as the average of 24-hour urinary urea and creatinine clearance and expressed as $\mathrm{mL} / \mathrm{min} / 1.73 \mathrm{~m}^{2}$.

In accordance with our aim to preserve RRF as much as possible, it is the policy in our PD unit to routinely assess RRF at 3-month intervals. For the majority of patients receiving planned administration of ICM, RRF is routinely assessed before exposure to ICM and at 1 week and 4 weeks thereafter, in order to detect any changes in the RRF that may necessitate modifications to the PD regimen and adjustment of the diuretic dosage. A reduction of $>30 \%$ in RRF at 7 days after exposure to ICM is considered CIN.

For some patients during the study period who needed urgent ICM administration, assessment of RRF was not performed before exposure to ICM, and patients did not receive acetylcysteine on the day before exposure to ICM; however, RRF was routinely assessed at 1 week and 4 weeks after exposure to ICM in order to detect changes in the RRF, as well as to adjust the PD regimen and diuretic dosage. These patients are not included in the present study.

The 24-hour urine collection is not a routine test during acute kidney injury. However, since all patients in this study were on maintenance PD due to end-stage renal disease, their serum creatinine levels were relatively high; changes in serum creatinine may be less sensitive, as might be the estimated glomerular filtration rate. Moreover, due to the retrospective design of the study, we were able to use the data that were available in the medical records. Therefore, we set out to determine the changes in RRF from baseline to 1 week and 4 weeks after the exposure to ICM. In previous studies, 24-hour urine collection was used to assess RRF during acute kidney injury. For example, Moranne et al prospectively evaluated the effect of iodinated contrast agents on RRF in PD patients, 24 hours before and 2 weeks after exposure to ICM..$^{21}$ In that study, as in the current one, RRF was quantified as the average of 24-hour urinary creatinine and urea clearance.

Eligibility criteria were: age above 18 years, follow-up period of $\geq 3$ months before exposure to ICM, a 24-hour urine volume of $>300 \mathrm{~mL} /$ day, and $\mathrm{RRF}>3 \mathrm{~mL} / \mathrm{min} / 1.73 \mathrm{~m}^{2}$. Exclusion criteria were: episodes of peritonitis in the 3-month period prior to the administration of ICM, and/or modifications in hypertensive medications or PD dialysis regimens or methods during the month preceding the exposure to ICM 
or between RRF assessments. Patients who needed urgent ICM administration were also excluded, because they did not receive acetylcysteine the day before the exposure to ICM, and the assessment of RRF was not performed before the exposure to ICM.

The following data were collected from patient medical records: age, sex, background illnesses, blood pressure, PD method (continuous ambulatory peritoneal dialysis [CAPD] or automated peritoneal dialysis [APD]), PD vintage, hemoglobin, plasma $\mathrm{C}$-reactive protein, serum albumin and 24-hour proteinuria levels, 24-hour urine volume, RRF, medications (ACEIs, ARBs, CCB, and diuretics).

Serum albumin levels below $3.5 \mathrm{~g} / \mathrm{dL}$ are generally considered low. However, according to the NKF K/DOQI guidelines 2,000, serum albumin levels equal to or greater than the lower limit of the normal range (approximately $4.0 \mathrm{~g} / \mathrm{dL}$ for the bromocresol green method) is considered the outcome goal in patients on maintenance dialysis. In two previous studies, conducted by Kim et al and Lee et al serum albumin levels lower than $4.0 \mathrm{~g} / \mathrm{dL}$ were used. ${ }^{19,20} \mathrm{In}$ an observational cohort study of 130,052 dialysis patients (12,171 PD and 117,851 HD) undertaken to determine the survival predictability of serum albumin levels in PD patients and to compare them with those in HD patients, a serum albumin level of $4.0 \mathrm{~g} / \mathrm{dL}$ was used for HD patients and a level of $3.8 \mathrm{~g} / \mathrm{dL}$ for PD patients. ${ }^{22}$ In a study of 58,058 HD patients, a baseline serum albumin level $<3.8 \mathrm{~g} / \mathrm{dL}$ was used to estimate the risk of death in this population. ${ }^{23}$ Moreover, the criteria for diagnosis of protein-energy wasting in patients with end-stage renal disease proposed by a panel of experts from the International Society of Renal Nutrition and Metabolism include a serum albumin level (measured using the bromocresol green method) of $<3.8 \mathrm{~g} / \mathrm{dL} .^{24,25}$

In the planning of this study and before analyzing the data, we set the criteria for comparing the outcomes between patients with serum albumin $<3.8 \mathrm{~g} / \mathrm{dL}$ and those with levels $\geq 3.8 \mathrm{~g} / \mathrm{dL}$ (measured using the bromocresol green method).

\section{Statistical analysis}

Statistical analysis was carried out using SPSS (v 19, IBM Corporation, Armonk, NY, USA) software. $P<0.05$ were considered to be significant. Continuous variables were reported as means and standard deviations, and categorical variables as frequencies and percentages. The chi-square test was used to evaluate and compare the frequencies between the study groups including PD modality, sex, medications, primary renal disease, and the presence of diabetes mellitus, hypertension, and plasma high-sensitivity $\mathrm{C}$-reactive protein (hsCRP) levels $>5 \mathrm{mg} / \mathrm{dL}$. The independent $t$-test was used to evaluate and compare the differences between the study groups, including age, mean arterial pressure (MAP), PD vintage, $\mathrm{Kt} / \mathrm{v}$, hemoglobin and $\mathrm{HbA}_{1 \mathrm{c}}$ levels, plasma hsCRP levels, 24-hour urine volume and proteinuria, and RRF. Paired $t$-tests were used to evaluate and compare changes in RRF between baseline and 1 week and 4 weeks after exposure to ICM in each of the study groups. Logistic regression was applied to identify variables that predict the development of CIN. A final model was constructed using clinical judgment and a stepwise selection method with predetermined significance.

\section{Results}

Of a total of 114 PD patients who underwent invasive angiographies with exposure to ICM, eleven patients were excluded. Of these, six received ICM for urgent reasons, two had modifications in their hypertensive medications, two had modifications in their dialysis regimen within the 4 weeks of the exposure to ICM, and one had peritonitis 1 month prior to exposure to ICM. Thus, 103 stable PD patients were included in the study.

Patients on CAPD received four exchanges of $2 \mathrm{~L} /$ day of glucose-based dialysis solutions (GBSs). Patients on APD received a 10-15 L/day GBS nightly regimen.

The serum range of patients with serum albumin levels $<3.8 \mathrm{~g} / \mathrm{dL}$ was $2.7-3.7 \mathrm{~g} / \mathrm{dL}$ and the serum range of patients with serum albumin levels $\geq 3.8 \mathrm{~g} / \mathrm{dL}$ was $3.8-4.5 \mathrm{~g} / \mathrm{dL}$. Serum albumin $<3.8 \mathrm{~g} / \mathrm{dL}$ was detected in $59.2 \%(61 / 103)$ of the patients (Figure 1). Of them, $37(60.7 \%)$ were female, 27 (44.3\%) had diabetes mellitus, 44 (72.1\%) had hypertension, 35 (57.4\%) were on CAPD, and 26 (42.6\%) were on APD (Table 1). No statistically significant differences were found between patients with serum albumin $<3.8 \mathrm{~g} / \mathrm{dL}$ and those with levels $\geq 3.8 \mathrm{~g} / \mathrm{dL}$ in terms of the primary kidney disease and baseline characteristics (Table 1).

All patients received loop diuretics; 64.1\% (66/103) were treated with ACEIs/ARBs and 40.8\% (42/103) treated with CCB (Table 1).

At baseline, both study groups (patients with serum albu$\min <3.8 \mathrm{~g} / \mathrm{dL}$ and patients with serum albumin $\geq 3.8 \mathrm{~g} / \mathrm{dL}$ ) were similar in terms of their age; the PD method they were on; sex; the presence of diabetes mellitus and hypertension; the use of diuretics; ACEIs/ARBs and CCBs; MAP; $\mathrm{PD}$ vintage; Kt/v; hemoglobin, $\mathrm{HbA}_{1 \mathrm{c}}$, and plasma hsCRP levels; 24-hour urine volume; 24-hour proteinuria; and RRF (Table 1). 


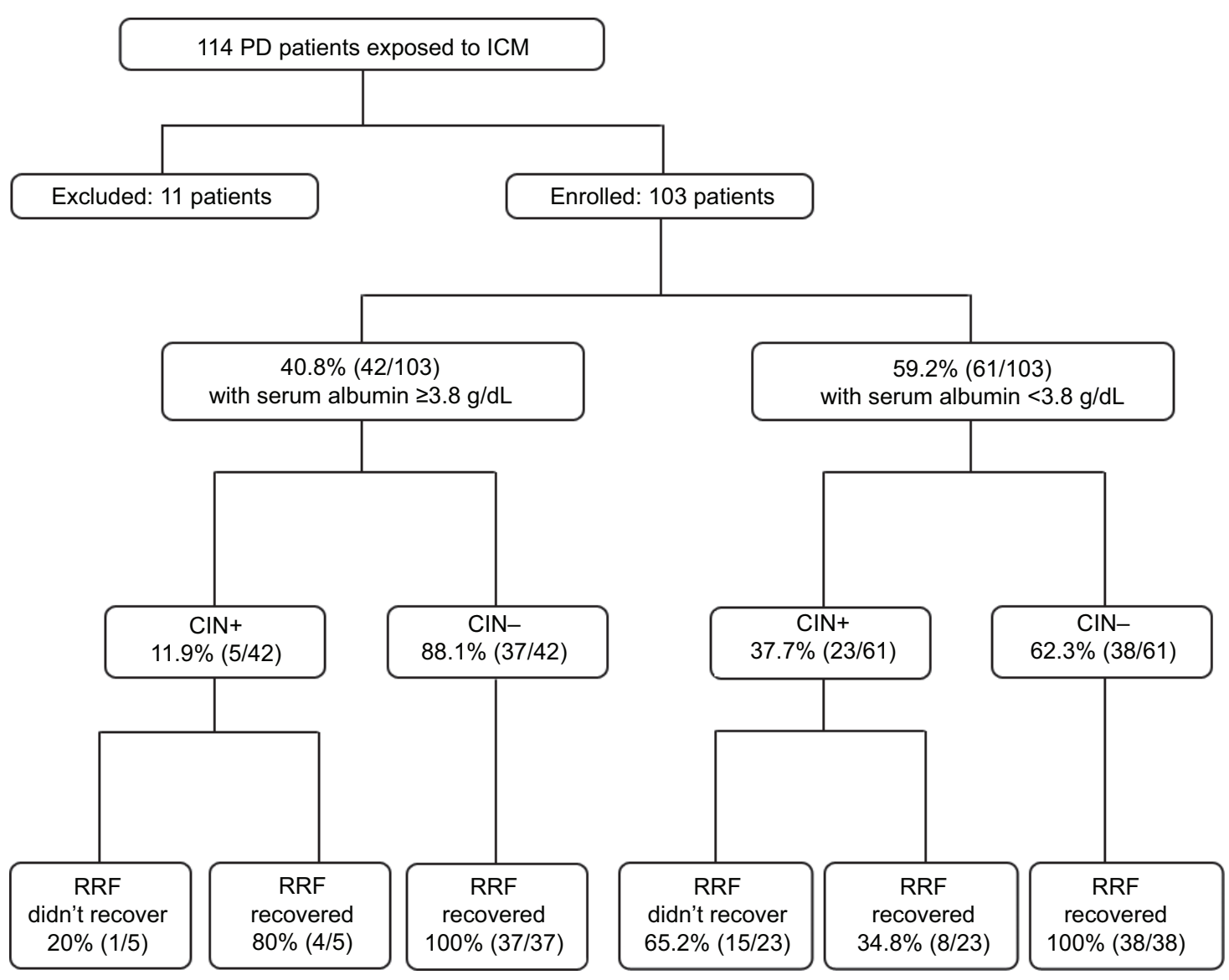

Figure I The patient cohort according to serum albumin levels, the development of iodine contrast media-induced nephropathy (CIN), and the residual renal function (RRF) in peritoneal dialysis (PD) patients exposed to iodine contrast media (ICM).

CIN developed in $27.2 \%(28 / 103)$ of the patients in the cohort (Figure 1). The mean serum albumin levels of patients who developed CIN was lower than that of patients who did not develop CIN $(3.3 \pm 0.5 \mathrm{~g} / \mathrm{dL}$ and $3.8 \pm 0.5 \mathrm{~g} / \mathrm{dL}$, respectively; $P<0.001$ ) (Table 2 ). Of patients with serum albumin $<3.8 \mathrm{~g} / \mathrm{dL}, 23$ (37.7\%) developed CIN compared with $11.9 \%$ (5/42) of those with serum albumin $\geq 3.8 \mathrm{~g} / \mathrm{dL}$ ( $P=0.004$ ) (Figure 1, Table 3).

In patients who developed CIN, PD vintage was higher than in patients who did not develop CIN $(P=0.004)$ (Table 2). Patients who developed CIN had a higher proportion of diabetes mellitus and higher plasma hsCRP levels than those who did not develop CIN, but these differences were not statistically significant (Table 2). No statistically significant differences were found between patients who developed CIN and those who did not develop CIN in terms of age; PD method; sex; use of diuretics, ACEIs, ARBs, or CCBs; Kt $/ \mathrm{v}$; blood pressure; hemoglobin, $\mathrm{HbA}_{1 \mathrm{c}}$, and plasma hsCRP levels; 24-hour urine volume; levels of 24-hour proteinuria; and baseline RRF (Table 2). In comparing the subgroups of patients with serum albumin $<3.8 \mathrm{~g} / \mathrm{dL}$ who developed CIN with patients with serum albumin $<3.8 \mathrm{~g} / \mathrm{dL}$ who did not develop CIN, serum albumin levels were lower in those who developed CIN $(P=0.002)$ and $\mathrm{PD}$ vintage was higher $(P=0.047)$ (Table 4$)$.

Of the patients who developed CIN, RRF was recovered in $80 \%(4 / 5)$ of those with serum albumin $\geq 3.8 \mathrm{~g} / \mathrm{dL}$ and in $34.8 \%(8 / 23)$ of those with serum albumin $<3.8 \mathrm{~g} / \mathrm{dL}$ (Figure 1). Baseline RRF was similar in patients with serum albumin $<3.8 \mathrm{~g} / \mathrm{dL}$ and those with serum albumin $\geq 3.8 \mathrm{~g} / \mathrm{dL}$ (Figures 2 and 3). In comparing RRF before the exposure to ICM, and at 1 week and 4 weeks thereafter, among patients with serum albumin $\geq 3.8 \mathrm{~g} / \mathrm{dL}$, no significant variation in RRF was observed (Figure 2). In contrast, in patients with serum albumin $<3.8 \mathrm{~g} / \mathrm{dL}$, a significant reduction was observed in RRF at 1 week after exposure to ICM; at 4 weeks, a significant but only partial improvement was observed in RRF (Figure 2).

After adjustment for all tested variables in a logistic regression with a stepwise selection model, serum albumin level at exposure to ICM was found to be the most powerful predictor of the development of CIN (odds ratio $=4.5$; confidence interval $=1.5-13.0, P=0.006$ ). 
Table I Baseline characteristics of peritoneal dialysis patients with serum albumin $<3.8 \mathrm{~g} / \mathrm{dL}$ and those with serum albumin $\geq 3.8 \mathrm{~g} / \mathrm{dL}$ before the exposure to iodine contrast media

\begin{tabular}{|c|c|c|c|}
\hline \multirow[t]{2}{*}{ Variable } & \multirow[t]{2}{*}{$P$-value } & \multicolumn{2}{|c|}{ Serum albumin } \\
\hline & & $\geq 3.8 \mathrm{~g} / \mathrm{dL}$ & $<3.8 \mathrm{~g} / \mathrm{dL}$ \\
\hline Patients (n) & & 42 & 61 \\
\hline Age (years) & $0.557^{* *}$ & $58.4 \pm 10.2$ & $57.1 \pm 11.1$ \\
\hline CAPD, \% (n) & $0.828^{*}$ & $59.5(25)$ & $57.4(35)$ \\
\hline APD, \% (n) & $0.828^{*}$ & $40.5(17)$ & $42.6(26)$ \\
\hline Females, \% (n) & $0.55 I^{*}$ & $54.8(23)$ & $60.7(37)$ \\
\hline Diabetes mellitus, \% (n) & $0.888^{*}$ & $42.9(18)$ & $44.3(27)$ \\
\hline Hypertension, \% (n) & $0.735^{*}$ & $69.0(29)$ & $72.1(44)$ \\
\hline Loop diuretics, \% (n) & - & $100(42)$ & $100(61)$ \\
\hline ACEI/ARB, \% (n) & $0.971 *$ & $64.3(27)$ & $63.9(39)$ \\
\hline $\mathrm{CCB}, \%(\mathrm{n})$ & $0.959 *$ & $40.5(17)$ & $41.0(25)$ \\
\hline MAP, mmHg & $0.634 * *$ & $98.2 \pm 7.1$ & $97.4 \pm 7.9$ \\
\hline Vintage, months & $0.820 * *$ & $38.3 \pm 14.2$ & $37.7 \pm 11.6$ \\
\hline $\mathrm{Kt} / \mathrm{v}$ & $0.569 * *$ & $2.0 \pm 0.3$ & $2.1 \pm 0.4$ \\
\hline Hemoglobin, g/dL & $0.518 * *$ & $11.5 \pm 1.5$ & $11.3 \pm 1.6$ \\
\hline Serum albumin, g/dL & $<0.001$ & $4.2 \pm 0.2$ & $3.3 \pm 0.3$ \\
\hline $\mathrm{HbA}_{\mathrm{Ic}}, \%$ & $0.404 * *$ & $6.5 \pm 0.9$ & $6.7 \pm 1.0$ \\
\hline Plasma hsCRP, mg/dL & $0.704 * *$ & $7.4 \pm 5.3$ & $7.9 \pm 7.1$ \\
\hline 24-hour urine volume, $\mathrm{mL}$ & $0.258 * *$ & $623.8 \pm 155.9$ & $671.3 \pm 266.5$ \\
\hline 24 -hour proteinuria, g/day & $0.395 * *$ & $0.66 \pm 0.25$ & $0.7 I \pm 0.32$ \\
\hline Baseline RRF, mL/min/I.73 & $0.740 * *$ & $8.10 \pm 2.16$ & $8.30 \pm 2.35$ \\
\hline \multicolumn{4}{|l|}{ Primary renal disease, \% (n) } \\
\hline Diabetic nephropathy & $0.888 * *$ & $42.9(18)$ & $44.3(27)$ \\
\hline Hypertension & $0.954 * *$ & $33.3(14)$ & $32.8(20)$ \\
\hline Glomerulopathy & $1.000 * *$ & $9.5(4)$ & $9.8(6)$ \\
\hline Chronic interstitial disease & $1.000 * *$ & $4.8(2)$ & $4.9(3)$ \\
\hline Unknown etiology & $1.000 * *$ & $9.5(4)$ & $8.2(5)$ \\
\hline
\end{tabular}

Notes: $*$ Chi-square test, $* *$ independent $t$-test. For serum albumin, values are represented mean \pm standard deviation unless unless otherwise specified.

Abbreviations: ACEI, angiotensin-converting enzyme inhibitor; APD, automated peritoneal dialysis; ARB, angiotensin-receptor antagonist; CAPD, continuous ambulatory peritoneal dialysis; $C C B$, calcium-channel blocker; hsCRP, high-sensitivity C-reactive protein; MAP, mean arterial pressure; RRF, residual renal function; HbA ${ }_{I c}$, glycosylated haemoglobin level.

\section{Discussion}

The main finding of this study is the significantly lower mean level of serum albumin among patients undergoing PD who developed CIN than among those who did not develop CIN. Hypoalbuminemia in PD patients can be multifactorial and might reflect increased systemic inflammation, volume overload, ongoing peritoneal and urinary losses of protein, and impaired compensatory hepatic synthesis of albumin. The retrospective study design did not enable evaluation of the reasons for hypoalbuminemia.

The incidence of CIN has been increasing in recent years, as a result of the widespread use of contrast media in diagnostic and treatment practices, and developments in angiographic techniques. Risk assessment for CIN in PD patients is currently based on sparse data from a few studies, and on extrapolation of findings from CKD patients. ${ }^{6}$ To the best of our knowledge, the impact of serum albumin levels on the development of CIN in PD patients has not been studied. The results of the present study reveal that a substantial proportion of PD patients had serum albumin $<3.8 \mathrm{~g} / \mathrm{dL}$. Similarly, in an observational cohort study of 130,052 dialysis patients (12,171 PD and 117,851 HD), 63\% of PD patients had serum albumin $<3.8 \mathrm{~g} / \mathrm{dL} .^{22}$ In the current study, CIN developed in $27.2 \%$ of all studied PD patients compared with in 3\%-14\% of the general population. ${ }^{10-12}$ Furthermore, three times as many patients with serum albumin $<3.8 \mathrm{~g} / \mathrm{dL}$ developed CIN as did patients with serum albumin $\geq 3.8 \mathrm{~g} / \mathrm{dL}$ (Figure 1, Table 3).

Two mechanisms have been proposed to explain the occurrence of CIN. Renal blood flow decreases by $30 \%$ to $45 \%$ within 2 to 4 hours of ICM injection, leading to the development of renal hypoxia. ${ }^{13-16}$ In patients with advanced CKD, RRF remarkably depends on the single nephron glomerular filtration rate, which, in itself, is particularly dependent on renal blood flow. If the renal blood flow decreases, as happens when ICM is administered, the RRF may subsequently decrease. A second possible mechanism for the occurrence of $\mathrm{CIN}$ is that free radicals resulting from contrast-agent 
Table 2 Characteristics of patients who developed contrast-induced nephropathy (CIN) compared with those who did not develop CIN after exposure to iodine contrast media

\begin{tabular}{|c|c|c|c|}
\hline Variable & $P$-value & CIN- $(n=75)$ & $\mathrm{CIN}+(\mathrm{n}=28)$ \\
\hline Age, years & $0.874 * *$ & $57.7 \pm 11.1$ & $57.4 \pm 9.6$ \\
\hline CAPD, \% (n) & $0.757^{*}$ & $57.3(43)$ & $60.7(17)$ \\
\hline APD, \% (n) & $0.757^{*}$ & $42.7(32)$ & $39.3(\mathrm{II})$ \\
\hline Female, \% (n) & $0.448 *$ & $56.0(42)$ & $64.3(18)$ \\
\hline Diabetes mellitus, \% (n) & $0.093 *$ & $38.7(29)$ & $57.1(16)$ \\
\hline Hypertension, \% (n) & $0.940 *$ & $70.7(53)$ & $7 I .4(20)$ \\
\hline Loop diuretics, \% (n) & - & $100(75)$ & $100(28)$ \\
\hline ACEI/ARB, \% (n) & $0.979 *$ & $64.0(48)$ & $64.3(18)$ \\
\hline $\mathrm{CCB}, \%(\mathrm{n})$ & $0.85 I^{*}$ & $4 I .3(3 I)$ & $39.3(11)$ \\
\hline MAP, mmHg & $0.256 * *$ & $97.2 \pm 7.5$ & $99.1 \pm 7.5$ \\
\hline Vintage, months & $0.004 * *$ & $35.8 \pm 12.1$ & $43.7 \pm 12.6$ \\
\hline $\mathrm{Kt} / \mathrm{v}$ & $0.545 * *$ & $2.1 \pm 0.4$ & $2.0 \pm 0.3$ \\
\hline Hemoglobin, g/dL & $0.968 * *$ & $11.4 \pm 1.6$ & $11.4 \pm 1.5$ \\
\hline $\mathrm{HbA}_{\mathrm{Ic}} \%$ & $0.407^{* *}$ & $6.6 \pm 0.9$ & $6.8 \pm 1.0$ \\
\hline Plasma hsCRP, mg/dL & $0.668 * *$ & $7.5 \pm 6.4$ & $8.1 \pm 6.6$ \\
\hline Plasma hsCRP $>5 \mathrm{mg} / \mathrm{dL}, \%(\mathrm{n})$ & $0.078^{*}$ & $56(42)$ & $75(2 I)$ \\
\hline Dose of contrast agent, $\mathrm{mL}$ & $0.878 * *$ & $75.8 \pm 17.2$ & $74.3 \pm 16.7$ \\
\hline 24-hour urine volume, $\mathrm{mL}$ & $0.85 \mid * *$ & $649.3 \pm 232.6$ & $658.9 \pm 220.3$ \\
\hline 24-hour proteinuria, g/day & $0.712^{* *}$ & $0.7 \pm 0.3$ & $0.67 \pm 0.2$ \\
\hline Serum albumin, $g / d L$ & $<0.00 \mathrm{I} * *$ & $3.8 \pm 0.5$ & $3.3 \pm 0.5$ \\
\hline Baseline RRF, mL/min/l.73 & $0.530 * *$ & $8.15 \pm 2.26$ & $8.46 \pm 2.30$ \\
\hline
\end{tabular}

Notes: ${ }^{*}$ Chi-square test, ${ }^{*}$ independent $t$-test. Values are represented mean \pm standard deviation unless unless otherwise specified.

Abbreviations: ACEI, angiotensin-converting enzyme inhibitor; APD, automated peritoneal dialysis; ARB, angiotensin-receptor antagonist; CAPD, continuous ambulatory peritoneal dialysis; $C C B$, calcium-channel blocker; hsCRP, high-sensitivity C-reactive protein; MAP, mean arterial pressure; RRF, residual renal function; HbA ${ }_{I c}$ glycosylated haemoglobin level.

injection induce cytotoxic effects, which cause renal tubule damage. ${ }^{13-16}$

Moreover, serum albumin is the most abundant serum protein and responsible for $70 \%$ of the total osmotic pressure. ${ }^{26}$ Among its various vital functions in the body, serum albumin maintains the oncotic pressure in the vascular system and has antioxidant properties. ${ }^{27}$ Some studies have reported a preventive role of serum albumin for CIN through vascular expansion and its antioxidant properties. ${ }^{28}$ The mechanism involved in the association between nephropathy and low albumin is not fully understood; however, low albumin is likely to be responsible for the development of CIN by causing renal tubular cytotoxic damage with free radicals.

One study reported that $\mathrm{N}$-acetylcysteine may improve RRF in patients treated with PD. ${ }^{29}$ On the other hand,

Table 3 Contrast-induced nephropathy (CIN) within 7 days of exposure to iodine contrast media in peritoneal dialysis patients with serum albumin $<3.8 \mathrm{~g} / \mathrm{dL}$ and those with serum albumin $\geq 3.8 \mathrm{~g} / \mathrm{dL}$

\begin{tabular}{llll}
\hline Serum albumin & CIN+, n (\%) & CIN-, n (\%) & P-value \\
\hline$<3.8 \mathrm{~g} / \mathrm{dL}$ & $23 / 6 \mathrm{I}(37.7 \%)$ & $38 / 6 \mathrm{I}(62.3 \%)$ & $0.004^{*}$ \\
$\geq 3.8 \mathrm{~g} / \mathrm{dL}$ & $5 / 42(\mathrm{II} .9 \%)$ & $37 / 42(88.1 \%)$ & $0.004^{*}$ \\
\hline
\end{tabular}

Note: ${ }^{*}$ Chi-square test. low serum albumin has been identified as a risk factor for developing CIN in patients without CKD who underwent bronchial arteriography or embolization. ${ }^{30}$ One prospective study showed no accelerated decline in RRF over the 2-week period following ICM exposure in 36 stable PD patients with adequate prehydration. ${ }^{21}$ Another prospective study reported that administration of ICM did not lead to a persistent decline of RRF in ten CAPD patients who received elective diagnostic intravenous or intra-arterial administration of ICM. ${ }^{31}$ A retrospective analysis did not show that administration of ICM has a long-term effect on RRF in dialysis patients. ${ }^{32}$ These studies were small and did not consider in their analyses the effect of serum albumin levels on the development of CIN. All patients exposed to ICM in the present study received adequate hydration and $\mathrm{N}$-acetylcysteine. Nonetheless, most of the CIN cases occurred among hypoalbuminemic patients with serum albumin levels $<3.8 \mathrm{~g} / \mathrm{dL}$. The low levels of serum albumin thus seem to contribute to the development of CIN, but the mechanisms of its involvement need elucidation.

$\mathrm{PD}$ vintage was greater in patients who developed CIN compared with those who did not. The possibility that PD vintage may be a risk factor for CIN is an area for future investigation. Rates of diabetes mellitus and plasma hsCRP 
Table 4 Characteristics of patients with serum albumin $<3.8 \mathrm{~g} / \mathrm{dL}$ who developed contrast-induced nephropathy (CIN) compared with those with serum albumin $<3.8 \mathrm{~g} / \mathrm{dL}$ who did not develop CIN after exposure to iodine contrast media

\begin{tabular}{|c|c|c|c|}
\hline Variable & $P$-value & CIN- $(n=38)$ & $\mathrm{CIN}+(\mathrm{n}=23)$ \\
\hline Age, years & $0.894 * *$ & $57.3 \pm 11.7$ & $56.9 \pm 10.2$ \\
\hline CAPD, \% (n) & $0.668^{*}$ & $55.3(2 I)$ & $60.9(14)$ \\
\hline APD, \% (n) & $0.668^{*}$ & $44.7(17)$ & 39.1 (9) \\
\hline Female, \% (n) & $0.570^{*}$ & $57.9(22)$ & $65.2(15)$ \\
\hline Diabetes mellitus, \% (n) & $0.134^{*}$ & $36.8(14)$ & $56.5(13)$ \\
\hline Hypertension, \% (n) & $0.809 *$ & 7I.I (27) & $73.9(17)$ \\
\hline Loop diuretics, \% (n) & - & $100(38)$ & $100.0(23)$ \\
\hline ACEI/ARB, \% (n) & $0.87 I^{*}$ & $63.2(24)$ & $65.2(15)$ \\
\hline $\mathrm{CCB}, \%(\mathrm{n})$ & $0.819 *$ & $42.1(16)$ & 39.1 (9) \\
\hline MAP, mmHg & $0.166 * *$ & $96.3 \pm 7.7$ & $99.2 \pm 8.0$ \\
\hline Vintage, months & $0.047^{* *}$ & $35.4 \pm 11.8$ & $41.5 \pm 10.3$ \\
\hline $\mathrm{Kt} / \mathrm{v}$ & $0.552 * *$ & $2.1 \pm 0.4$ & $2.0 \pm 0.3$ \\
\hline Hemoglobin, g/dL & $0.73 I^{* *}$ & $11.2 \pm 1.7$ & $11.4 \pm 1.5$ \\
\hline $\mathrm{HbA}_{1 \mathrm{c}}, \%$ & $0.677^{* *}$ & $6.6 \pm 1.0$ & $6.8 \pm 1.0$ \\
\hline Plasma hsCRP, mg/dL & $0.750 * *$ & $7.7 \pm 7.1$ & $8.3 \pm 7.2$ \\
\hline Plasma hsCRP $>5 \mathrm{mg} / \mathrm{dL}, \%(\mathrm{n})$ & $0.134 *$ & $50.0(19)$ & $69.6(16)$ \\
\hline 24-hour urine volume, $\mathrm{mL}$ & $0.992 * *$ & $671.0 \pm 292.6$ & $671.7 \pm 223.0$ \\
\hline 24-hour proteinuria, g/day & $0.391 * *$ & $0.74 \pm 0.35$ & $0.67 \pm 0.26$ \\
\hline Serum albumin, g/dL & $0.002 * *$ & $3.4 \pm 0.3$ & $3.1 \pm 0.3$ \\
\hline Baseline RRF, $\mathrm{mL} / \mathrm{min} / \mathrm{I} .73$ & $0.490 * *$ & $8.13 \pm 2.38$ & $8.57 \pm 2.33$ \\
\hline
\end{tabular}

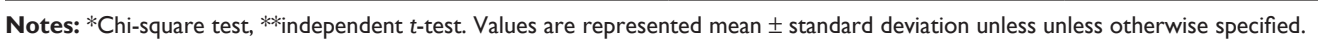

Abbreviations: ACEl, angiotensin-converting enzyme inhibitor; APD, automated peritoneal dialysis; ARB, angiotensin-receptor antagonist; CAPD, continuous ambulatory peritoneal dialysis; CCB, calcium-channel blocker; hsCRP, high-sensitivity C-reactive protein; MAP, mean arterial pressure; RRF, residual renal function; HbA ${ }_{I c}$, glycosylated haemoglobin level.

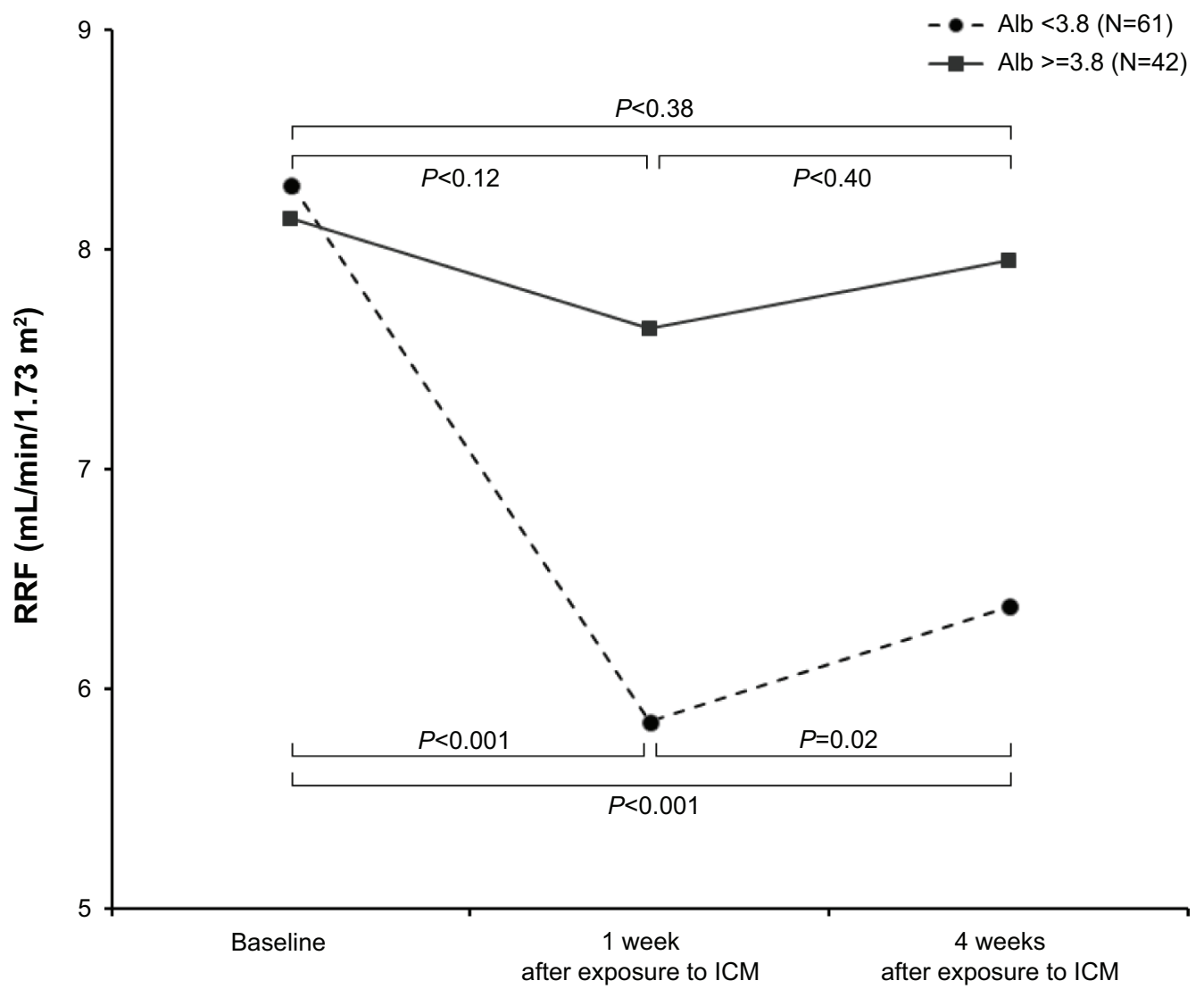

Figure 2 Evolution of residual renal function (RRF) from baseline levels to I week and 4 weeks after exposure to iodine contrast media (ICM) in peritoneal dialysis patients with serum albumin $<3.8 \mathrm{~g} / \mathrm{dL}$ and those with serum albumin $\geq 3.8 \mathrm{~g} / \mathrm{dL}$ (paired $t$-test). 
levels $>5 \mathrm{mg} / \mathrm{dL}$ were higher, though without statistical significance, among patients who developed CIN, suggesting that associations between these factors and the development of CIN should be investigated further.

Although baseline RRF was similar in patients with serum albumin $<3.8 \mathrm{~g} / \mathrm{dL}$ and those with serum albumin $\geq 3.8 \mathrm{~g} / \mathrm{dL}$, the rate of recovery from CIN after 4 weeks was considerably higher among those with higher albumin levels $(80 \%$ vs $34.8 \%$ ) (Figure 2). Further, among patients with serum albumin $<3.8 \mathrm{~g} / \mathrm{dL}$, mean RRF decreased significantly at 1 week after the exposure to ICM and was notably, but incompletely, improved at 4 weeks, contrasting with the absence of a significant variation in RRF among those with higher albumin levels (Figure 2).

Serum albumin level at exposure to ICM was the most powerful predictor of the development of CIN (odds ratio $=4.5 ;$ confidence interval $=1.5-13.0 ; P=0.006)$. The contribution of low serum albumin levels $(<3.8 \mathrm{~g} / \mathrm{dL})$ to the development of CIN shown herein raises the possibility that the simple measure of serum albumin may represent a potential therapeutic target in the prevention of CIN and preservation of RRF when PD patients are exposed to intravenous or intra-arterial ICM.

\section{Limitations}

The present study is retrospective. From the presented data, no conclusions can be drawn about possible long-term effects (beyond 4 weeks) of intravenous injection of ICM. However, it seems that patients who recover their RRF within 4 weeks may maintain their RRF more than those whose RRF does not recover. Furthermore, we cannot draw conclusions about the long-term effects (beyond 4 weeks) in patients who did not recover. However, the findings may provide useful information for future multicenter prospective studies aimed at investigating the prevalence rate, risk factors, and long-term effects of CIN in PD patients.

In addition, the retrospective design of this study did not enable the evaluation of the reasons for hypoalbuminemia.

\section{Conclusion}

PD patients with serum albumin levels $<3.8 \mathrm{~g} / \mathrm{dL}$ should be monitored carefully when exposed to ICM. Serum albumin levels may be considered a potential therapeutic target in the prevention of CIN and preservation of RRF in PD patients.

\section{Disclosure}

The authors report no conflicts of interest in this work.

\section{References}

1. Jansen MA, Hart AA, Korevaar JC, et al; NECOSAD Study Group. Predictors of the rate of decline of residual renal function in incident dialysis patients. Kidney Int. 2002;62(3):1046-1053.

2. Bargman JM, Thorpe KE, Churchill DN; CANUSA Peritoneal Dialysis Study Group. Relative contribution of residual renal function and peritoneal clearance to adequacy of dialysis: a reanalysis of the CANUSA study. J Am Soc Nephrol. 2001;12(10):2158-2162.

3. Venkataraman V, Nolph KD. Preservation of residual renal functionan important goal. Perit Dial Int. 2000;20(4):392-395.

4. Singhal MK, Bhaskaran S, Vidgen E, Bargman JM, Vas SI, Oreopoulos DG. Rate of decline of residual renal function in patients on continuous peritoneal dialysis and factors affecting it. Perit Dial Int. 2000;20(4):429-438.

5. Shin SK, Noh H, Kang SW, et al. Risk factors influencing the decline of residual renal function in continuous ambulatory peritoneal dialysis patients. Perit Dial Int. 1999;19(2):138-142.

6. Chandna SM, Farrington K. Residual renal function: considerations on its importance and preservation in dialysis patients. Semin Dial. 2004; 17(3):196-201.

7. Medcalf JF, Harris KP, Walls J. Role of diuretics in the preservation of residual renal function in patients on continuous ambulatory peritoneal dialysis. Kidney Int. 2001;59(3):1128-1133.

8. Suzuki H, Kanno Y, Sugahara S, Okada H, Nakamoto H. Effects of an angiotensin II receptor blocker, valsartan, on residual renal function in patients on CAPD. Am J Kidney Dis. 2004;43(6):1056-1064.

9. Li PK, Chow KM, Wong TY, Leung CB, Szeto CC. Effects of an angiotensin-converting enzyme inhibitor on residual renal function in patients receiving peritoneal dialysis. A randomized, controlled study. Ann Intern Med. 2003;139(2):105-112.

10. Bettman MA. Contrast medium-induced nephropathy: critical review of the existing clinical evidence. Nephrol Dial Transplant. 2005;20 Suppl 1:i12-i17.

11. Lindsay J, Apple S, Pinnow EE, et al. Percutaneous coronary intervention-associated nephropathy foreshadows increased risk of late adverse events in patients with normal baseline serum creatinine. Catheter Cardiovasc Interv. 2003;59(3):338-343.

12. Parfrey PS, Griffiths SM, Barrett BJ, et al. Contrast material-induced renal failure in patients with diabetes mellitus, renal insufficiency, or both. A prospective controlled study. $N$ Engl J Med. 1989;320(3): 143-149.

13. Persson PB, Hansell P, Liss P. Pathophysiology of contrast mediuminduced nephropathy. Kidney Int. 2005;68(1):14-22.

14. Russo D, Minutolo R, Cianciaruso B, Memoli B, Conte G, De Nicola L. Early effects of contrast media on renal hemodynamics and tubular function in chronic renal failure. J Am Soc Nephrol. 1995;6(5): 1451-1458.

15. Tumlin JA, Wang A, Murray PT, Mathur VS. Fenoldopam mesylate blocks reductions in renal plasma flow after radiocontrast dye infusion: a pilot trial in the prevention of contrast nephropathy. Am Heart J. 2002; 143(5):894-903.

16. Heinrich MC, Kuhlmann MK, Grgic A, Heckmann M, Kramann B, Uder M. Cytotoxic effects of ionic high-osmolar, nonionic monomeric, and nonionic iso-osmolar dimeric iodinated contrast media on renal tubular cells in vitro. Radiology. 2005;235(3):843-849.

17. Rodríguez E, Soler MJ, Rap O, Barrios C, Orfila MA, Pascual J. Risk factors for acute kidney injury in severe rhabdomyolysis. PLoS One. 2013;18;8(12):e82992.

18. Li QL, Cheng QL, Ma Q, et al. [Risk factors and short-term prognosis of acute kidney injury in elderly patients.] Zhonghua Yi Xue Za Zhi. 2013;10;93(34):2715-2718. Chinese.

19. Kim CS, Oak CY, Kim HY, et al. Incidence, predictive factors, and clinical outcomes of acute kidney injury after gastric surgery for gastric cancer. PLoS One. 2013;8(12):e82289.

20. Lee EH, Baek SH, Chin JH, et al. Preoperative hypoalbuminemia is a major risk factor for acute kidney injury following off-pump coronary artery bypass surgery. Intensive Care Med. 2012;38(9):1478-1486. 
21. Moranne O, Willoteaux S, Pagniez D, Dequiedt P, Boulanger E. Effect of iodinated contrast agents on residual renal function in PD patients. Nephrol Dial Transplant. 2006;21(4):1040-1045.

22. Mehrotra R, Duong U, Jiwakanon S, et al. Serum albumin as a predictor of mortality in peritoneal dialysis: comparisons with hemodialysis. $\mathrm{Am}$ J Kidney Dis. 2011;58(3):418-428.

23. Kalantar-Zadeh K, Kilpatrick RD, Kuwae N, et al. Revisiting mortality predictability of serum albumin in the dialysis population: time dependency, longitudinal changes and population-attributable fraction. Nephrol Dial Transplant. 2005;20(9):1880-1888.

24. Han SH, Han DS. Nutrition in patients on peritoneal dialysis. Nat Rev Nephrol. 2012;8(3):163-175.

25. Fouque D, Kalantar-Zadeh K, Kopple J, et al. A proposed nomenclature and diagnostic criteria for protein-energy wasting in acute and chronic kidney disease. Kidney Int. 2008;73(4):391-398.

26. Farrugia A. Albumin usage in clinical medicine: tradition or therapeutic? Transfus Med Rev. 2010;24(1):53-63.

27. Nicholson JP, Wolmarans MR, Park GR. The role of albumin in critical illness. Br J Anaesth. 2000;85(4):599-610.
28. Choi H, Kim Y, Kim SM, et al. Intravenous albumin for the prevention of contrast-induced nephropathy in patients with liver cirrhosis and chronic kidney disease undergoing contrast-enhanced CT. Kidney Res Clin Pract. 2012;31(2):106-111.

29. Feldman L, Shani M, Efrati S, et al. N-acetylcysteine improves residual renal function in peritoneal dialysis patients: a pilot study. Perit Dial Int. 2011;31(5):545-550.

30. Song JS, Kim SI, Kim W, et al. Incidence and risk factors of contrastinduced nephropathy after bronchial arteriography or bronchial artery embolization. Tuberc Respir Dis (Seoul). 2013;74(4):163-168.

31. Dittrich E, Puttinger H, Schillinger M, et al. Effect of radio contrast media on residual renal function in peritoneal dialysis patients - a prospective study. Nephrol Dial Transplant. 2006;21(5):1334-1339.

32. Rich MW, Crecelius CA. Incidence, risk factors, and clinical course of acute renal insufficiency after cardiac catheterization in patients 70 years of age or older. A prospective study. Arch Intern Med. 1990;150(6): $1237-1242$.
Therapeutics and Clinical Risk Management

\section{Publish your work in this journal}

Therapeutics and Clinical Risk Management is an international, peerreviewed journal of clinical therapeutics and risk management, focusing on concise rapid reporting of clinical studies in all therapeutic areas, outcomes, safety, and programs for the effective, safe, and sustained use of medicines. This journal is indexed on PubMed Central, CAS,

\section{Dovepress}

EMBase, Scopus and the Elsevier Bibliographic databases. The manuscript management system is completely online and includes a very quick and fair peer-review system, which is all easy to use. Visit http://www.dovepress.com/testimonials.php to read real quotes from published authors.

Submit your manuscript here: http://www.dovepress.com/therapeutics-and-clinical-risk-management-journal 